\title{
Histomorphometric Variations of Placenta in Normal and Hypertensive Pregnancies
}

\author{
Rizwan Ali Talpur ${ }^{1}$, Samia Siddiqui ${ }^{2}$, Sehar Khowaja ${ }^{3}$, Naila Noor ${ }^{1}$, Muhammad Saqib Baloch ${ }^{3}$, Mansoor \\ Mukhtar Qazi ${ }^{4}$ \\ ${ }^{1}$ Senior Lecturer, Department of Physiology, Isra University Hyderabad, Pakistan \\ ${ }^{2}$ Associate Professor, Department of Physiology, Isra University Hyderabad, Pakistan \\ ${ }^{3}$ Senior Lecturer, Department of Anatomy, Isra University Hyderabad, Pakistan \\ ${ }^{4}$ Lecturer, Department of Anatomy, Isra University Hyderabad, Pakistan
}

\begin{abstract}
A BST RACT
Background: Pregnancy-induced hypertension is a leading cause of deleterious changes in the placenta resulting in decreased blood supply towards the organ. The objective of the current study was to analyze the histomorphometric variations in the placenta of normotensive and hypertensive women in a tertiary care hospital of Hyderabad, Pakistan. Material and Methods: This cross-sectional study was carried out in the Gynecology and Obstetrics section of Nazeer Hussain Medical Complex, Hyderabad in collaboration with Isra University, Hyderabad Pakistan from March 2019 to August 2019. A total of 100 placentae were collected and divided into two groups. Group I had placentae of normotensive women and group II comprised of placentae of hypertensive women. All the placentae were observed for morphometric and histological changes. Student t-test was done to study morphometric differences between the two groups, while chi-square test was used to analyze the categorical variables. $P$-value $<.05$ was considered as statistically significant.

Results: There was an increase in the mean weight of placentae among group I as compared to group II and the difference was statistically significant $(P<.05)$. Various gross and histological changes (hyalinized villi, intervillous hemorrhage, decreased villous vascularity) with a statistically significant difference were also observed in the placentae of the hypertensive group as compared to the normotensive placentae $(P<.05)$.

Conclusions: This study concluded that pregnancy-induced hypertension poses harmful and serious histomorphometric variations in the placental tissues that may affect fetal outcome.

Key words: Normotensive pregnancy, Placenta, Pre-eclampsia, Pregnancy-induced hypertension.

$\begin{array}{lll}\text { Authors' Contribution: } & \text { Correspondence: } & \text { Article info: } \\ { }^{1} \text { Conception; Literature research; } & \text { Mansoor Mukhtar Qazi } & \text { Received: April 20, 2020 } \\ \text { manuscript design and drafting; }{ }^{2,3} \text { Critical } & \text { Email: dr.lumhs119@yahoo.com } & \text { Accepted: November 20, 2020 } \\ \text { analysis and manuscript review; }{ }^{4} \text { Data } & & \\ \text { analysis; Manuscript Editing. } & & \end{array}$
\end{abstract}

Cite this article Talpur RA, Siddiqui S, Khowaja S, Noor N, Baloch MS, Qazi MM. Histomorphometric Variations of Placenta in Normal and Hypertensive Pregnancies. I Islamabad Med Dental Coll. 2020; 9(4): 242-248. Doi: 10.35787/jimdc.v9i4.540

Funding Source: Nil Conflict of Interest: Nil

Introduction

Gestational hypertension, also known as pregnancyinduced hypertension (PIH), is a serious condition that not only risks the life of a mother but also of the embryo/fetus growing in a mother's womb. ${ }^{1}$ It is 
said to occur when a pregnant lady has, with or without any previous history of hypertension, blood pressure (BP) readings of over 140/90 $\mathrm{mmHg}$ on two distinct occasions. PIH is mainly categorized into 3 major types: chronic or pre-existing hypertension, gestational hypertension (recently diagnosed) and pre-eclampsia (a more complicated form of $\mathrm{PIH}$ which may lead to eclampsia). ${ }^{2} \mathrm{PIH}$ affects over $5 \%$ of all pregnancies worldwide which results in immature/ premature deliveries. ${ }^{3}$

Placenta is a vital organ connecting the fetus to the endometrium of the maternal uterine wall, providing passage of essential nutrients and oxygen to meet the demands of the developing baby. ${ }^{4}$ Hypertension during pregnancy affects the development of the placenta by disturbing the blood supply to the placental tissue, which leads to compromised uteroplacental circulation. ${ }^{5}$ The compromised circulation is probably due to various histopathological changes in the placenta of the hypertensive pregnant, mother which interrupts the passage of essential nutrients from mother to fetus complicating the process of pregnancy. ${ }^{6,7}$ Moreover, pregnant women with pre-eclampsia are often observed to have a distinct pathological lesion called placental infarct which is secondary to arterial atherosis. ${ }^{8}$ It is estimated that seventy percent (70\%) of the global fetal mortality is associated with infarction of placental tissue among women with PIH. ${ }^{9}$ World Health Organization (WHO) conducted a Survey on Maternal and Newborn Health in 29 countries across Africa, Asia, Latin America, and the Middle East. It was reported that almost $0.30 \%$ of women were having chronic hypertension (range $0.21 \%$ in Africa to $0.32 \%$ in Western Pacific countries), while in Pakistan, the PIH has been reported to complicate $2 \%-3 \%$ of deliveries. ${ }^{10}$ Placental ischemia leading to small-sized placenta is a classical feature seen in women with preeclampsia. ${ }^{11,12}$
As mentioned, placenta is the main connecting point between mother and developing fetus. Any abnormality in the placental tissue due to vascular pathology or morphology may result in toxemia that compromise the normal development of the fetus and may also further complicate the pregnancy. The findings of the current study will be helpful for clinicians in identifying histological alterations in the placenta secondary to maternal hypertension and possible obstruction to the fetal blood flow resulting from placental vessel obstruction. Furthermore, controlling hypertension or its related complications in early phase may save maternal and fetal life. The objective of the current study was to compare and analyze the histomorphometric variations in the placentae of normotensive and hypertensive women.

\section{Material and Methods}

A cross-sectional study was carried out in the Gynecology and Obstetrics section of Nazeer Hussain Medical Complex (NHMC), Hyderabad in collaboration with Isra University, Hyderabad Pakistan from March 2019 to August 2019. A total of 100 women were admitted and delivered at the NHMC during the study duration. All the placentae were collected along with the umbilical cord. The collected placentae were divided into two groups: Group-I had placentae from normotensive women and Group-II had placentae from hypertensive women. Weight of new-born babies and fetoplacental weight ratios were also noted soon after delivery.

Placentae of women with history of hypertension or Pregnancy-induced hypertension (blood pressure $\geq$ 140/90 mmHg after 20 weeks of gestation) with or without edema, fits and/or proteinuria were included in the study. Placentae belonging to women with history of other co-morbidities (like diabetes mellitus, thyroid-related problems, any feto-maternal complication, pre-mature deliveries 
$<30$ weeks of gestation, those who received injection ergometrine or similar drugs for uterine contractions) were excluded from the study.

The study was approved by the Ethical Review Committee of Isra University, Hyderabad while the permission from the administration of Nazeer Hussain Medical Complex, Hyderabad was also obtained for conducting the study. The details of the study were explained to all the study participants in their native languages before obtaining informed written consent.

After collection, placentae were washed gently in normal water and weighed using an electronic balance. Gross features were observed by assessing changes in marginal veins, cotyledons, the status of placental membranes, presence or absence of infarction, and calcification. Area of umbilical cord attachment in each placenta was also noted.

Placentae were then transferred to a glass jar with $10 \%$ formalin solution. All jars were labeled and transferred to the postgraduate research laboratory of Isra University, Hyderabad for further evaluation. Placental Tissue sections were passed in alcohol of increasing concentration (70\%, 80\%, 95\%, 100\%) and then in Xylene solution for removing excess alcohol.

Placental tissues were embedded in melted paraffin. Approximately 4-micron thick sections were cut from paraffin blocks via microtome and slides were prepared. Slides were stained with Hematoxylin and Eosin for histopathological examination under light microscope.

SPSS version 23 was used for statistical analysis. Mean \pm Standard Deviation (SD) was used to represent the descriptive statistics. Analysis of statistical difference between the groups was done by using Student's t-test and chi-square test. The level of significance was set at $P$-value $<.05$.

\section{Results}

The mean differences in maternal age, gestational age, birth weights of the newborns, placental weight, feto-placental weight ratio and cotyledons per placenta between group I and group II are demonstrated in Table I. A statistically significant difference between maternal age $(P=.0001)$, gestational age $(P=.0001)$, birth weight $(P=.001)$, placental weight $(P=.001)$ and feto-placental weight ratio $(P=.04)$ was observed between placentae of group I and group II (Table I).

\begin{tabular}{|c|c|c|c|}
\hline \multicolumn{4}{|c|}{$\begin{array}{l}\text { Table I: Mean maternal, gestational fetal age and } \\
\text { morphometric information of placenta of both } \\
\text { groups }\end{array}$} \\
\hline Parameter & Groups & Mean+SD & $P$-value ${ }^{*}$ \\
\hline \multirow{2}{*}{$\begin{array}{l}\text { Maternal age } \\
\text { (years) }\end{array}$} & Group I & $22.6 \pm 2.94$ & \multirow{2}{*}{.0001} \\
\hline & Group II & $25.4 \pm 3.12$ & \\
\hline \multirow{2}{*}{$\begin{array}{l}\text { Gestational } \\
\text { age (weeks) }\end{array}$} & Group I & $36.81 \pm 1.20$ & \multirow{2}{*}{.0001} \\
\hline & Group II & $34.22+1.29$ & \\
\hline \multirow{2}{*}{$\begin{array}{l}\text { Birth weight } \\
\text { (grams) }\end{array}$} & Group I & $2784+43.0$ & \multirow{2}{*}{.001} \\
\hline & Group II & $2438 \pm 24.1$ & \\
\hline \multirow{2}{*}{$\begin{array}{l}\text { Placental } \\
\text { weight (grams) }\end{array}$} & Group I & $465.0 \pm 64.01$ & \multirow{2}{*}{.001} \\
\hline & Group II & $417.0 \pm 57.01$ & \\
\hline \multirow{2}{*}{$\begin{array}{l}\text { Feto-placental } \\
\text { weight ratio }\end{array}$} & Group I & $6.26 \pm 0.402$ & \multirow{2}{*}{.04} \\
\hline & Group II & $6.11 \pm 0.316$ & \\
\hline \multirow{2}{*}{$\begin{array}{l}\text { Cotyledons } \\
\text { per placenta }\end{array}$} & Group I & $16.0 \pm 3.01$ & \multirow{2}{*}{.05} \\
\hline & Group II & $15.0 \pm 2.01$ & \\
\hline
\end{tabular}

${ }^{*} P<.05$ was taken as statistically significant

The morphological presentation of the placentae with an area of infarction, calcification and marginal attachment of the umbilical cord is shown in Figure 1B. There was a statistically significant difference between the presence of infarction, calcification, retroplacental hematoma and marginal attachment of umbilical cord between the two groups $(P<.05)$ (Table II).

Marked histopathological changes were observed between the placentae of normotensive and hypertensive mothers $(P<.05)$ (Table III) (Figure 2). 

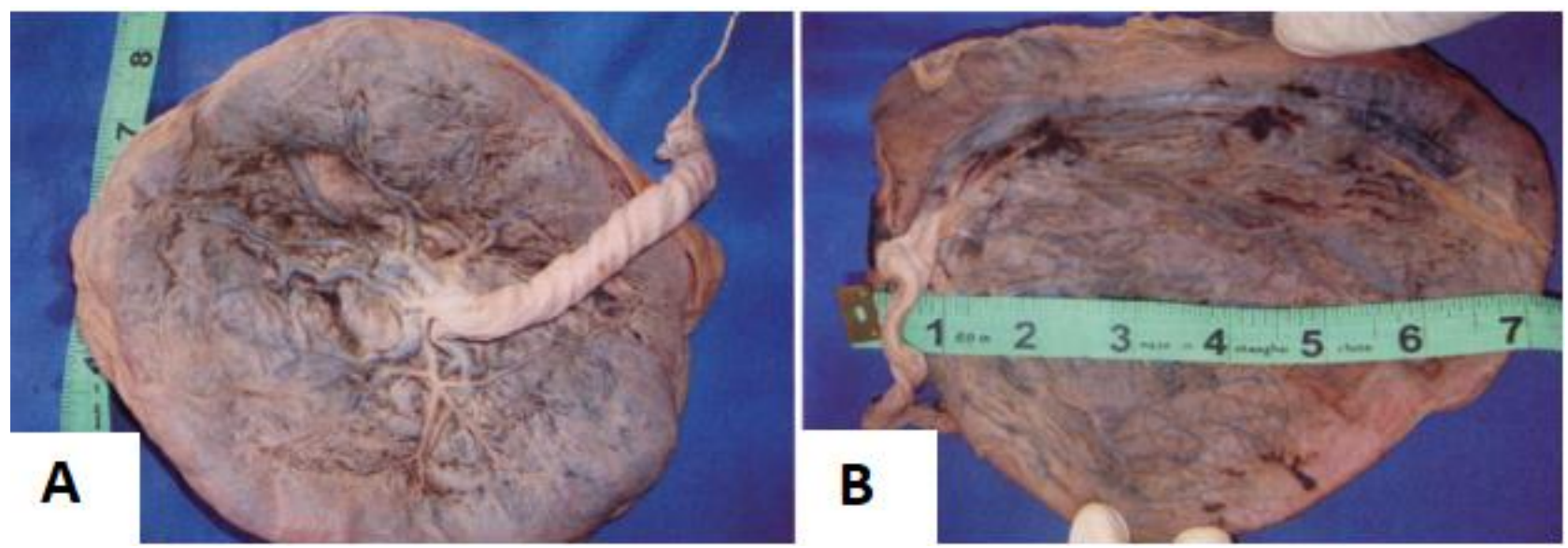

Figure 1: Morphological presentation in normotensive (A) and hypertensive (B) placentae
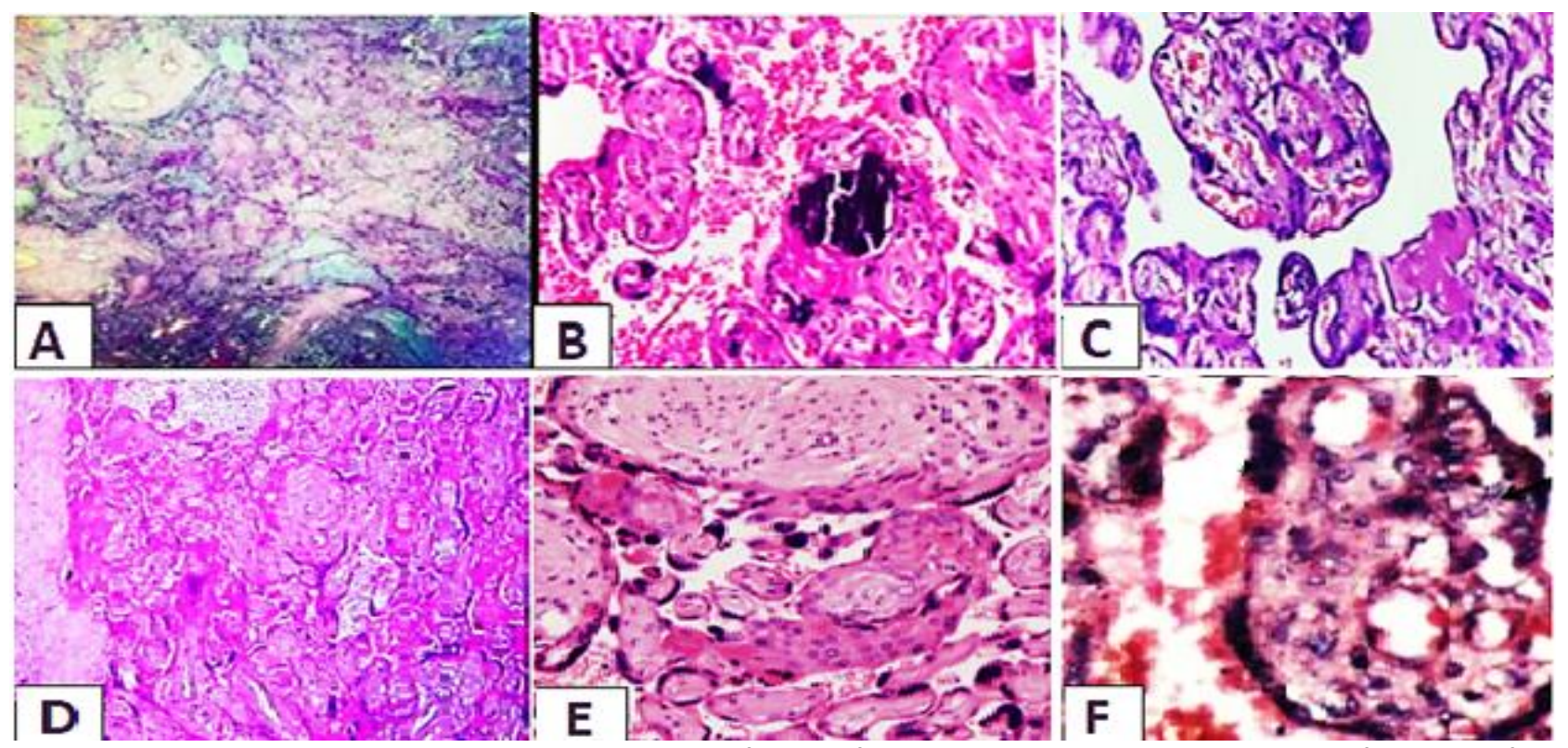

Figure 2: Photomicrographs of placentae of PIH group (group II). A: Homogenous areas of infarction (H\&E, 100x). B: Calcification (H\&E 400x). C: Syncytial knots seen as clumping of syncytial-trophoblastic nuclei over the villous surface (H\&E 400x). D: Endothelial wall of the villous vessel is shown to have been replaced by deep, red fibrinoid necrosis which appears as a homogenous nodular mass in the villi (H\&E 100x). E: Hyalinized villi showing degeneration of RBCs, vascular endothelial cells and fibroblasts of villous stroma (H\&E 400x). F: Cytotrophoblastic proliferation seen as uniform thickening of basement membrane underneath the cytotrophoblasts (H\&E 400x)

\begin{tabular}{|l|c|c|c|c|}
\hline \multicolumn{4}{|c|}{ Table II: Comparison of Gross features of placentae in both groups (n=100) } \\
\hline \multirow{2}{*}{ Gross Features } & Findings & $\begin{array}{c}\text { Group I } \\
\mathbf{n}(\%)\end{array}$ & $\begin{array}{c}\text { Group II } \\
\text { n (\%) }\end{array}$ & \\
\hline \multirow{2}{*}{ Infarction } & Present & $04(8)$ & $21(42)$ & \multirow{2}{*}{.001} \\
\cline { 2 - 4 } & Absent & $46(92)$ & $29(58)$ & \\
\hline \multirow{2}{*}{ Calcification } & Present & $11(22)$ & $30(60)$ & \multirow{2}{*}{.001} \\
\cline { 2 - 4 } $\begin{array}{l}\text { Hematoma } \\
\text { (Retroplacental) }\end{array}$ & Absent & $39(78)$ & $20(40)$ & \multirow{2}{*}{.037} \\
\hline $\begin{array}{l}\text { Umbilical cord attachment } \\
\text { (Marginal) }\end{array}$ & Present & $05(10)$ & $13(26)$ & \multirow{2}{*}{.045} \\
\cline { 2 - 4 } & Absent & $45(90)$ & $37(74)$ & $14(28)$ \\
\hline
\end{tabular}




\begin{tabular}{|c|c|c|c|c|}
\hline \multicolumn{5}{|c|}{ Table III: Histopathological changes in placentae in both groups } \\
\hline Parameters & Findings & $\begin{array}{c}\text { Group I } \\
\text { n (\%) }\end{array}$ & $\begin{array}{c}\text { Group II } \\
\text { n (\%) }\end{array}$ & P-value ${ }^{*}$ \\
\hline \multirow{2}{*}{ Syncytial knots formation per / 100 villi } & Present & $11(22)$ & $31(62)$ & \multirow{2}{*}{.001} \\
\hline & Absent & $39(78)$ & $19(38)$ & \\
\hline \multirow{2}{*}{ Fibrinoid necrosis/100 villi } & Present & $9(18)$ & $34(68)$ & \multirow{2}{*}{.001} \\
\hline & Absent & $41(82)$ & $16(32)$ & \\
\hline \multirow{2}{*}{ Hyalinized villi/10 Low Power Fields } & Present & $4(8)$ & $12(24)$ & \multirow{2}{*}{.029} \\
\hline & Absent & $46(92)$ & $38(76)$ & \\
\hline \multirow{2}{*}{ Cytotrophoblastic proliferation/100 villi } & Present & $7(14)$ & $33(66)$ & \multirow{2}{*}{.001} \\
\hline & Absent & $43(86)$ & $17(34)$ & \\
\hline
\end{tabular}

$* P$-value $<.05$ was considered statistically significant

\section{Discussion}

Hypertension during pregnancy is a serious condition that risks the life of a pregnant woman and her growing embryo/fetus. It poses damaging impacts on the development of the placental tissue by disturbing its blood supply which leads to compromised uteroplacental circulation. ${ }^{5}$ Keeping this in mind, placentae from normotensive as well as hypertensive women were analyzed in this study for the presence of any histomorphometric alterations.

In the current study, mean birth weight of the newborns was greater in the normotensive group as compared to the hypertensive group. This is consistent with the findings of Gore and coworkers, who conducted a study in a tertiary care center of western India. ${ }^{14}$ Moreover, research studies carried out by Ezeigwe et al. and Kambale et al. also demonstrated a significant difference in the mean birth weight of the newborn in their studies. ${ }^{13,15} \mathrm{~A}$ study by Goswami et al. reported pregnancyinduced hypertension as an independent risk factor for causing low birth weight. ${ }^{16}$

The mean fetoplacental weight ratio was decreased in the placentae of hypertensive group compared with their normal counterparts in the present study. Mehare et al. and Goswami et al. also reported decrease in FTP ratio in hypertensive groups compared to the normal placentae. ${ }^{16,17}$ These findings are consistent with those observed in our study. This decline in FTP may be due to placental insufficiency associated with altered dimension of placental tissue, neonatal morbidity and ultimately with preterm deliveries.

Infarcted areas were also observed more in the placentae of hypertensive women. Similar findings have been reported by Bar et al., Dhawle et al. and Butt et al. ${ }^{8,18,19}$ Infarctions may be due to thrombotic blockage of maternal blood vessels involved in uteroplacental circulation from $\mathrm{PIH}$, which leads to progressive uteroplacental ischemia causing hypoxia in developing fetuses, intrauterine growth restriction and fetal mortality.

Marginal attachment of the umbilical cord in the placenta was found to be $28 \%$ in hypertensive groups in our study. Awuah et al. and Agarwal et al. also reported that majority of placentae were having marginal attachment of the umbilical cord. ${ }^{12,20}$

Syncytial knots were more commonly observed in the hypertensive group placentae. The formation of syncytial knots is directly related to the hypoxia of placental tissue as a result of thrombotic occlusion of uteroplacental vessels and also due to reactive oxygen species. Ranjan et al., Pramar et al. and Chhatwal et al. in their studies also observed and reported the findings that are consistent with our study. ${ }^{11,21,22}$

Limited funds and time duration were one of the major constraints of the present study. The current 
study focused on histomorphometric changes in the placenta, while the status of the newborn babies in terms of APGAR score should also be evaluated in association with microscopic studies of the placenta.

\section{Conclusion}

This study concluded that Pregnancy-induced hypertension poses harmful and serious histomorphometric variations in the placental tissues that may affect fetal outcome.

\section{References}

1. Meher P, Meher SK, Jena SK. Cord blood parameters change in Pregnancy-induced hypertension. Int J Res Med Sci. 2017; 5(5): 2099. Doi: 10.18203/23206012.ijrms20171850.

2. Keche HA, Keche AS. Morphometric differentiation between placenta in PIH and normal pregnancy. Int J Med Sci Public Health. 2015; 4(2): 62-7. Doi: 10.5455/ijmsph.2015.0711201457.

3. Razak A, Florendo-Chin A, Banfield L, Wahab MA, McDonald S, Shah $P$, et al. Pregnancy-induced hypertension and neonatal outcomes: a systematic review and meta-analysis. J Perinatol. 2018; 38(1): 4653. Doi: 10.1038/jp.2017.162.

4. Rohini $P$, Siddharth $T$, Fathima A, Dhiren P. Human Placentae in Pregnancy-induced Hypertension-A Histologic and Morphometric Analysis. Int J Anat Appl Physiol. 2018; 4(3): 95-8. Doi: 10.19070/2572-74511800017.

5. Bandekar PK, Kale PB. Placenta in Pregnancy-induced hypertension. Int J Reprod Contracept Obstet Gynecol. 2018; 7(2): 467-9. Doi: 10.18203/23201770.ijrcog20180156.

6. Porwal V, Jain D, Gupta S, Khandelwal S, Kasliwal N. Spectrum of placental changes in Pregnancy-induced hypertension. Annals Pathol Lab Med. 2017; 4(1): A69-A76.

7. Bian J, Lei J, Yin X, Wang P, Wu Y, Yang X, et al. Limited AT1 receptor internalization is a novel mechanism underlying sustained vasoconstriction induced by AT1 receptor autoantibody from preeclampsia. J Am Heart Assoc. 2019; 8(6): e011179. Doi: 10.1161/JAHA.118.011179.
8. Butt SY, Ejaz S, Waheed K. Frequency of placental infarct and fetal outcome in hypertensive primigravidas. RMJ. 2016; 41(3): 335-8.

9. Akshara V, Ramakrishnan P, Chitra S, Kumar Sai Sailesh SKS, Seema Valsalan E. Morphology and the morphometric measurements of hypertensive and normotensive placenta. Biomed Res. 2018; 29 (18): 3522-25.

10. Magee LA, Sharma S, Nathan HL, Adetoro OO, Bellad MB, Goudar S, Macuacua SE, Mallapur A, Qureshi R, Sevene E, Sotunsa J. The incidence of pregnancy hypertension in India, Pakistan, Mozambique, and Nigeria: A prospective population-level analysis. PLoS medicine. 2019 Apr 12; 16(4): e1002783.

11. Ranjan DS, Gyanaranjan N, Bhusan MB, Sreepreeti C. Histopathological Study of Placenta in Pregnancy with Hypertension in western odisha. hypertension. IOSRJDMS. 2017; 16(6): 100-04.

12. Awuah SP, Okai I, Ntim EA, Bedu-Addo K. Prevalence, placenta development, and perinatal outcomes of women with hypertensive disorders of pregnancy at Komfo Anokye Teaching Hospital. PLoS ONE. 2020; 15(10):e0233817.Doi: 10.1371/journal.pone.0233817

13. Ezeigwe $\mathrm{CO}$, Okafor $\mathrm{Cl}$, Eleje GU, Udigwe GO, Anyiam DC. Placental peripartum pathologies in women with preeclampsia and eclampsia. Obstet Gynecol Int. 2018; Article ID 9462938. Doi: 10.1155/2018/9462938

14. Gore C, Pandey A, Shetty A, Rao R, Paranjape S. A study on histopathological changes in placenta in preeclampsia/eclampsia: A case-control study in tertiary care centre, western India. IJOP. 2018; 5(3): 385-90. Doi: 10.18231/2394-6792.2018.0075.

15. Kambale T, Iqbal B, Ramraje S, Swaimul K, Salve S. Placental morphology and fetal implications in pregnancies complicated by pregnancy-induced hypertension. Med J DY Patil Univ. 2016; 9(3): 341-47. Doi: 10.4103/0975-2870.182505.

16. Goswami P, Memon S, Rathore M. Foeto-placental weight relationship in normal pregnancy and pregnancies complicated by Pregnancy-induced hypertension and abruption of placentae. Int J Res Med Sci. 2015; 3(5): 1081.

17. Mehare T, Kebede D. Fetoplacental Weight Relationship in Normal Pregnancy and Pregnancy Complicated by Pregnancy-Induced Hypertension and Abruption of Placenta among Mothers Who Gave Birth in Southern Ethiopia, 2018. Obstet Gynecol Int. 
2020; Article ID 6839416. Doi: 10.1155/2020/ 6839416.

18. Bar PK GS, Gayen P, Mandal S, De A. Morphological study of placenta in hypertensive disorders in pregnancy. Trop J Path Micro 2019; 5(6): 366-373. Doi:10.17511/jopm.2019.i06.06.

19. Dhawle MS, Tangde AR, Mundhe BP, Rathod SG, Bindu RS. Morphological study of placenta in Pregnancyinduced hypertension. Int J Res Med Sci. 2017; 5(7): 3214-7. Doi: 10.18203/2320-6012.ijrms20173015.
20. Agarwal G, Saini P, Pankaj J, Pandey L, Jain A. Morphological study of placenta in normal and hypertensive pregnancies. IAIM. 2015; 2(5): 121-8.

21. Parmar KM, Shah GV, Alamchandani RR. Histological evaluation of placenta in hypertensive pregnancies. Int J Res Med Sci. 2019; 7(1): 40. Doi: 10.18203/23206012.ijrms20185360

22. Chhatwal J, Chaudhary D, Chauhan N. Placental changes in hypertensive pregnancy: a comparison with normotensive pregnancy. Int J Reprod Contracept Obstet Gynecol. 2018; 7(9): 3808. Doi: 10.18203/2320-1770.ijrcog20183799. 